\title{
Mimosoideae (Leguminosae) arbóreas do Parque Estadual do Rio Doce, Minas Gerais, Brasil: DISTRIBUiÇão Geográfica e SiMILARIDAde FLORÍSTICA NA FLORESTA ATLÂNTICA NO SUDESTE DO BRASIL ${ }^{1}$
}

\author{
Sânzia Romanova Duarte Ferreira da Silva Nunes², Flávia Cristina Pinto Garcia3, \\ Haroldo Cavalcante de Lima ${ }^{4} \&$ Rita Maria de Carvalho-Okano ${ }^{3}$
}

\begin{abstract}
RESUMO
(Mimosoideae (Leguminosae) arbóreas do Parque Estadual do Rio Doce, Minas Gerais, Brasil: distribuição geográfica e similaridade florística na floresta atlântica no sudeste do Brasil) O PERD, com 35.974 ha, localiza-se no leste de Minas Gerais (1948' e 19²9’ S; 42³8' e 42²8’W) no Domínio Atlântico, na formação da floresta estacional semidecídua submontana, onde Leguminosae é uma das famílias com maior importância na composição florística. Durante o inventário das espécies de Mimosoideae no PERD foram encontrados 26 táxons arbóreos, que neste trabalho são analisados quanto aos limites de distribuição geográfica e avaliados como indicadores das relações florísticas entre o PERD e outras áreas de floresta atlântica do sudeste brasileiro. Seis padrões de distribuição geográfica foram reconhecidos com base na literatura taxonômica e consultas a herbários: Neotropical (8 spp.), América do Sul Ocidental-Centro-Oriental (4 spp.), Brasil Centro-Oriental (3 spp.), Brasil Atlântico NordesteSudeste-Sul (3 spp.), Brasil Atlântico Nordeste-Sudeste (5 spp.), Brasil Atlântico Sudeste (3 spp.). Os táxons, quanto à preferência de habitat, foram tratados como elementos florísticos generalistas (73\%) e especialistas do Domínio Atlântico (27\%). Os resultados mostraram maior similaridade entre o PERD e trechos de floresta situados em baixas elevações. Existem similaridades florísticas entre florestas ombrófila densa e estacionais semidecíduas do sudeste, apoiando a proposição de origem comum dessas fitofisionomias.
\end{abstract}

Palavras-chave: Florística, floresta semidecídua, flora arbórea, fitogeografia.

\section{Abstract}

(Woody Mimosoideae (Leguminosae) of the Parque Estadual do Rio Doce, Minas Gerais, Brazil: geographical distribution and floristic similarity of the Atlantic Forest Southeastern Brazil) The Parque Estadual do Rio Doce, with

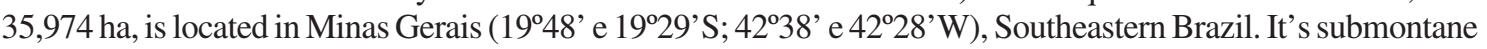
semideciduos forest belongs to the Atlantic Forest domain, where Leguminosae is one of the families with the greatest importance in the floristic composition. The aim of this work is to study the geographical distribution patterns of 26 taxa found in the PERD and to highlight indicator species for the floristic relationship between the PERD and other Atlantic Forest areas of Southeastern Brazil. Six geographical distribution patterns were established with basis on taxonomic literature and herbarium records: Neotropical (8 spp.), western-central-eastern South America (4 ssp.), central-eastern Brazil (3 spp.), northeastern-southeastern-southern Atlantic Brazil (3 spp.), northeasternsoutheastern Atlantic Brazil (5 spp.), southeastern Atlantic Brazil (3 spp.). According to their habitat preference, the taxa were classified as general floristic elements (73\%) and specialists from the Atlantic domain (27\%). The results show greater similarity between the PERD and lowland forests. Floristic similarity between perennial and semideciduous forests in southeastern Brazil supports the proposal for a common origin of these phyisionomies. Key words: Floristic, semideciduous forest, tree flora, phytogeography.

\section{INTRODUÇÃO}

Leguminosae com cerca de 727 gêneros e 19.325 espécies é considerada a terceira maior família de angiospermas (Lewis et al. 2005). No Brasil está representada aproximadamente de 188 gêneros e 2.100 espécies (Lima 2000), distribuídas em quase todas as formações vegetacionais (Barroso et al. 1991). Tradicionalmente, Leguminosae está dividida em três subfamílias: Caesalpinioideae, Mimosoideae e Papilinioideae (Polhill \& Raven 1981). Análises filogenéticas têm demonstrado tanto o monofiletismo da família e das duas últimas subfamílias quanto o parafiletismo de

\footnotetext{
Artigo recebido em 09/2006. Aceito para publicação em 02/2007.

${ }^{1}$ Parte da dissertação de mestrado desenvolvida no Programa de Pós-Graduação em Botânica, Departamento de Biologia Vegetal, Universidade Federal de Viçosa.

${ }^{2}$ Centro Universitário do Leste de Minas Gerais. Rua Bárbara Heliodora, 725, Imbaúbas, 35160-215, Ipatinga, MG, Brasil.universalis@uaivip.com.br

${ }^{3}$ Departamento de Biologia Vegetal, Universidade Federal de Viçosa, 36570-000, Viçosa, MG, Brasil.

${ }^{4}$ Instituto de Pesquisas Jardim Botânico do Rio de Janeiro, Rua Pacheco Leão 915, 22460-030, Rio de Janeiro, RJ, Brasil.
} 
Caesalpinioideae (Doyle et al. 2000; Herendeen et al. 2003; Wojciechowski 2003; Wojciechowski et al. 2004; Lewis et al. 2005).

Mimosoideae compreende quatro tribos, 78 gêneros e aproximadamente 3.270 espécies (Lewis et al. 2005), distribuídas nas regiões tropicais, subtropicais e cálido-temperadas (Polhill \& Raven 1981). Quase dois terços das espécies conhecidas estão subordinadas a três gêneros: Acacia, Mimosa e Inga (Elias 1974).

A flora brasileira é considerada uma das mais ricas do globo (Giulietti \& Forero 1990) e Leguminosae é apontada como uma das famílias mais representativas nas formações florestais neotropicais (Gentry 1982). Nas florestas da costa atlântica do Brasil, em geral denominadas mata atlântica ou floresta atlântica, esta família destaca-se entre os elementos mais importantes do estrato arbóreo (Leitão-Filho 1982; Peixoto \& Gentry 1990; Lima 2000; Oliveira \& Fontes 2000).

Em Minas Gerais, a floresta atlântica está localizada na porção leste-sudeste do estado, denominadaZona da Mata (Martins 2000), sendo representada principalmente pela floresta estacional semidecídua, ocorrendo também as formações ombrófilas densa e mista (Silva 2000). Estudos florísticos e fitossociológicos realizados na Zona da Mata mineira destacaram Leguminosae como uma das famílias mais representativas (Oliveira-Filho \& Machado 1993; OliveiraFilho et al. 1994 a,b,c; Oliveira-Filho \& Ratter 1995; Meira-Neto et al. 1997 a,b,c; Lombardi \& Gonçalves 2000; Meira-Neto \& Martins 2002; Silva et al. 2003; Carvalho et al. 2005).

O presente trabalho tem como objetivos verificar a distribuição geográfica das espécies arbóreas de Mimosoideae ocorrentes no PERD e comparar a similaridade na composição desta subfamília entre o PERD e outras áreas de floresta atlântica do sudeste do Brasil.

\section{Material e Métodos}

\section{Caracterização e considerações sobre a área de estudo}

O Parque Estadual do Rio Doce (PERD), com 35.974 ha é atualmente a maior área de floresta contínua no estado de Minas Gerais. Foi criado pelo decreto-lei n. ${ }^{\circ} 1.119$ de 14 de julho de 1944, estando sob a administração do Instituto Estadual de Florestas de Minas Gerais (IEF-MG) desde 1962.

Localizado na região leste de Minas

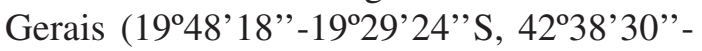
$\left.42^{\circ} 28^{\prime} 18^{\prime \prime} \mathrm{W}\right)$, no chamado Vale do Aço, abrange parte dos municípios de Marliéria, Dionísio e Timóteo, sendo limitado pelo rio Doce a leste e o rio Piracicaba ao norte.

Situa-se no domínio da floresta atlântica e sua vegetação pode ser classificada, de acordo com Veloso et al. (1991), como floresta estacional semidecídua submontana. Suas formações vão desde florestas de aspecto primário (ca. 38\%), até campo (ca. 5\%) (Gilhuis 1986), ocorrentes nos trechos central e norte, incluindo mosaicos de florestas primárias e secundárias, que fazem limite com plantações de eucalipto. As florestas secundárias, presentes em grande parte no trecho sul do Parque surgiram após as grandes queimadas ocorridas, principalmente, durante a década de 60 (IEF 1994) e com a exploração para produção de carvão vegetal. Sua vegetação destaca-se por ser considerada um dos poucos redutos de floresta atlântica, sob proteção legal, em Minas Gerais.

O PERD apresenta um complexo hídrico de aproximadamente 40 lagoas, que ocupam quase $6 \%$ de sua área. O clima, segundo o sistema de Köppen, é do tipo Aw, caracterizando um clima tropical úmido de savana, megatérmico. O regime pluviométrico apresenta variação de 1000 a $1200 \mathrm{~mm}$ de precipitação anual e deficiência hídrica da ordem de 50 a $100 \mathrm{~mm}$ (abril a setembro), assim como, excedentes hídricos de 100 a 200 mm (outubro a março) (Secretaria de Estado da Agricultura 1980). A área está inserida na "Depressão Interplanáltica do Vale do Rio Doce", importante feição fisiográfica da Região sudeste do Brasil (Mello 1997) e duas formas de relevo prevalecem: as colinas, em sua maioria convexa, originadas da dissecação fluvial de superfícies de aplainamento, datadas do Terciário Superior e Pleistoceno; e as planícies. As classes de relevo 
encontram-se assim distribuídas: ondulado, $21,12 \%$; forte-ondulado, $39,98 \%$ e forteondulado-montanhoso, 34,10\% (Gilhuis 1986; SIF/ IEF 1990).

\section{Coleta de dados}

Os dados de ocorrência dos 26 táxons arbóreos de Mimosoideae ocorrentes no PERD foram obtidos através do estudo florístico e taxonômico da subfamília, realizado por Nunes (2003). As coletas de material botânico foram realizadas mensalmente entre os meses de fevereiro de 2001 e abril de 2002 em oito trilhas, quatro delas localizadas no trecho central e as outras quatro no trecho sul. Coletas esporádicas também foram realizadas em outras trilhas presentes nesses dois trechos e com o intuito de ampliar a área amostrada, adentrou-se cerca de $20 \mathrm{~m}$ em ambos os lados das trilhas, sempre que possível.

A classificação genérica está de acordo com Lewis et al. (2005) e os nomes das espécies foram atualizados consultando revisões taxonômicas e o Ildis (2005).

Os dados referentes à distribuição geográfica dos táxons foram obtidos de revisões taxonômicas e de levantamentos florísticos. Seis padrões de distribuição foram reconhecidos segundo a faixa predominante de ocorrência, na qual os táxons exibem distribuições contínuas ou não e adaptados de Lima et al. (1997); Lima (2000) e Morim (2006). Foram observados os seguintes padrões: 1. Neotropical; 2. América do Sul Ocidental-Centro-Oriental; 3. Brasil CentroOriental; 4. Brasil Atlântico Nordeste-SudesteSul; 5. Brasil Atlântico Nordeste-Sudeste; 6. Brasil Atlântico Sudeste (Fig. 1).

Os mapas que ilustram a distribuição geográfica das espécies foram elaborados a partir de base cartográfica da Environmental Systems Research Institute (ESRI).

Quanto à preferência por habitat, as espécies foram classificadas de acordo com os diferentes domínios vegetacionais brasileiros definidos por Joly et al. (1999), em elementos florísticos generalistas, aquelas que além do Domínio Atlântico ocorrem em outros
Domínios como Amazônico, Cerrado e/ou Caatinga ou especialistas, espécies exclusivas do Domínio Atlântico.

A similaridade na composição de espécies arbóreas de Mimosoideae foi realizada entre o PERD e as seguintes localidades (cujas obras de referência estão citadas na tabela 3): Parque Estadual Fontes do Ipiranga-SP, CVRD-Linhares-ES, Mata do Carvão-RJ, PARNA Itatiaia-RJ, Cabo FrioRJ, Macaé de Cima-RJ, RPPN Feliciano Miguel Abdala (antiga Estação Biológica de Caratinga-MG), Reserva Florestal da ESALLavras-MG e Floresta do Jardim Botânico da UFV-Viçosa-MG. As fitofisionomias dessas áreas foram identificadas de acordo com Veloso et al. (1991).

A matriz simétrica com os índices de similaridade de Sorensen (Tab. 4) foi calculada através da informação florística, organizada ao nível de espécie, em uma matriz de presença e ausência (Tab. 5).

Para que os agrupamentos pudessem ser visualizados foi construído o dendrograma (Fig. 5) a partir do método de algorítmo de médias não ponderadas (UPGMA) (Sneath \& Sokal 1973).

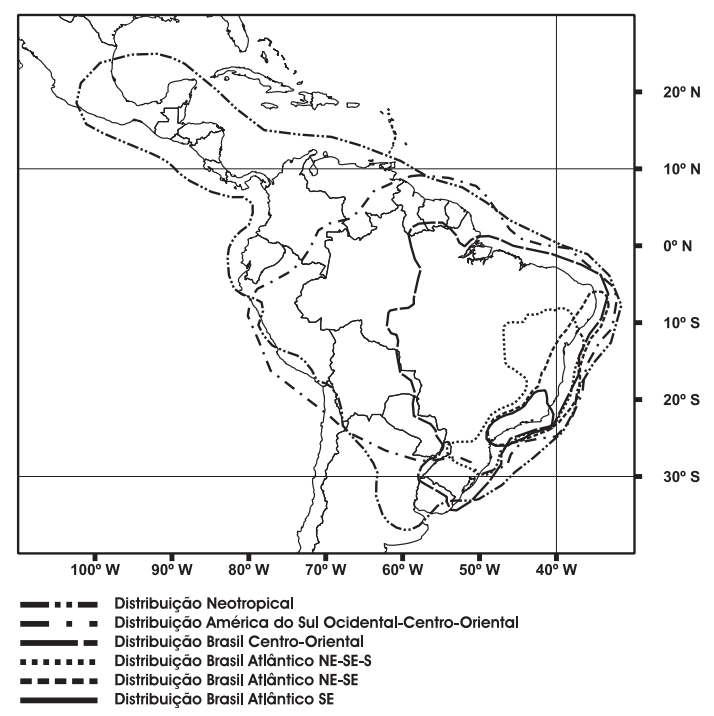

Figura 1 - Síntese de padrões de distribuição das Mimosoideae (Leguminosae) do PERD. 


\section{Resultados e Discussão}

\section{Padrões de distribuição geográfica}

A amplitude de distribuição geográfica dos táxons de Mimosoideae do PERD abrange três macrorregiões (Tab. 1): América do Sul, América Central e México (31\%); limitados à América do Sul (15\%) e restritos ao Brasil (54\%).

Do total de espécies estudadas $73 \%$ são generalistas e $27 \%$ especialistas de formações do Domínio Atlântico (Tab. 2). Estes resultados foram semelhantes aos obtidos por Morim (2006) em florestas montanas e alto-montanas do Parque Nacional do Itatiaia. As espécies generalistas apresentaram os padrões de distribuição Neotropical, seguido pelo da América do Sul Ocidental-Centro-Oriental. Já os táxons especialistas do Domínio Atlântico apresentaram os padrões de distribuição Brasil Atlântico Nordeste-Sudeste-Sul, Brasil Atlântico Nordeste-Sudeste e Brasil Atlântico Sudeste.

1. Distribuição Neotropical (Tab. 2): Este padrão foi reconhecido em oito táxons $(30 \%)$ com faixa de distribuição predominantemente na região tropical da América do Sul, podendo se estender até a América Central e México, com o limite sul de distribuição no norte da Argentina. Os seguintes táxons apresentaram este padrão: Acacia polyphylla (Fig. 2), Anadenanthera peregrina, Albizia pedicellaris, Inga capitata, I. edulis, I. marginata, I. thibaudiana e I. vera subsp. affinis. Todos encontrados em formações de diferentes domínios vegetacionais sendo consideradas generalistas. Acacia polyphylla, espécie heliófita (Lima 2000), foi encontrada no PERD na margem de estrada e em área aberta próxima ao Centro de Pesquisas. Ocorre nas Américas Central e do Sul estando distribuída

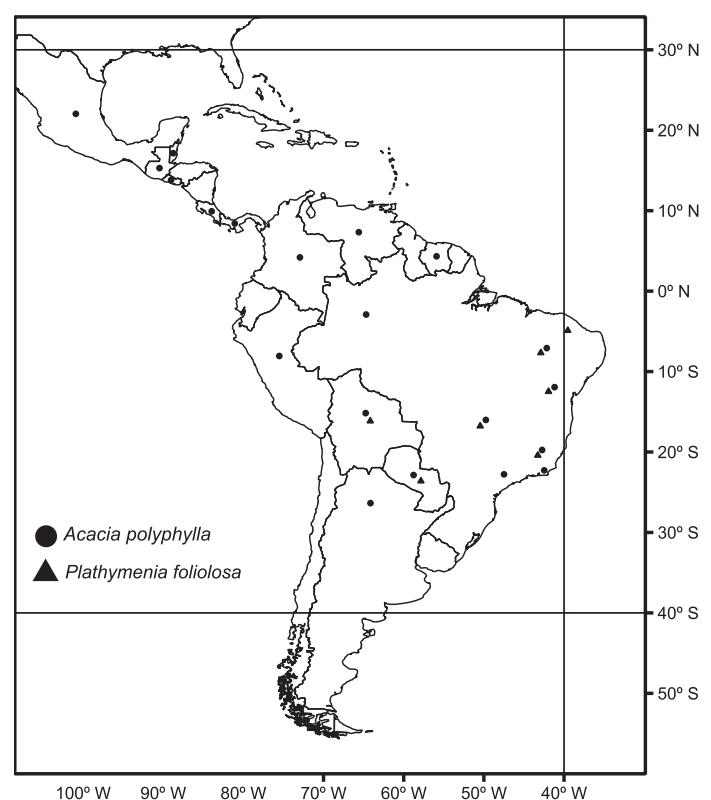

Figura 2 - Acacia polyphylla: Distribuição Neotropical; Plathymemia foliolosa: Distribuição América do Sul Ocidental-Centro-Oriental.

pela Argentina, Bolívia, Brasil, Colômbia, Paraguai, Peru, Suriname, Venezuela, Belize, Costa Rica, El Salvador, Guatemala, México e Panamá (Rico Arce 2001). No Brasil ocorre nos estados de Minas Gerais, São Paulo, Rio de Janeiro, Bahia, Piauí, Amazonas e Goiás (Bentham 1876; Barroso 1965; Lewis 1987; Silva 1990; Mendonça Filho 1996), sendo encontrada na floresta semidecídua de baixas altitudes (Oliveira-Filho \& Fontes 2000).

Anadenanthera peregrina foi encontrada em áreas abertas às margens de estradas que cortam o Parque e também no interior da floresta, nos trechos sul e central. Ocorre nas Ilhas do Caribe e na América do Sul, distribuindo-se pelo Brasil, Colômbia, Guiana Francesa, Guiana, Paraguai, Suriname e Venezuela (Altschul 1964), sendo observada

Tabela 1 - Número e porcentagem de táxons de Mimosoideae do PERD, por macrorregiões

\begin{tabular}{lccc}
\multicolumn{1}{c}{ Macrorregião } & $\mathbf{n}^{\mathbf{0}}$ táxons & \% \\
\hline I. América do Sul, América Central e & México & 8 & 31 \\
II. Limitado à América do Sul & 4 & 15 \\
III. Restritas ao Brasil & 14 & 54 \\
\hline Total & 26 & 100 \\
\hline
\end{tabular}


Tabela 2 - Padrões de distribuição, das Mimosoideae arbóreas do PERD, relação dos táxons e elementos florísticos, quanto às preferências por habitat.

\begin{tabular}{|c|c|c|}
\hline $\begin{array}{l}\text { Padrões de distribuição } \\
\text { (número de espécies) }\end{array}$ & Táxons* & $\begin{array}{l}\text { Elementos } \\
\text { florísticos }\end{array}$ \\
\hline \multirow[t]{8}{*}{ 1.Neotropical (8) } & 1. Acacia polyphylla DC. ${ }^{2,3,4,5,6,7}$ & Generalista \\
\hline & 2. Anadenanthera peregrina (L.) Speg. ${ }^{8}$ & Generalista \\
\hline & 3. Albizia pedicellaris (DC.) L. Rico ${ }^{1}$ & Generalista \\
\hline & 4. Inga capitata Desv. ${ }^{10,11}$ & Generalista \\
\hline & 5. Inga edulis Mart. ${ }^{10}$ & Generalista \\
\hline & 6. Inga marginata Willd. ${ }^{10,11}$ & Generalista \\
\hline & 7. Inga thibaudiana DC..$^{10,11}$ & Generalista \\
\hline & 8. Inga vera subsp. affinis (DC.) T.D. Penn. ${ }^{10,11}$ & Generalista \\
\hline 2. América do Sul & 9. Albizia polycephala (Benth.) Killip ${ }^{1,2,14,20}$ & Generalista \\
\hline Ocidental-Centro- & 10. Inga flagelliformis (Vell.) Mart. ${ }^{11}$ & Generalista \\
\hline \multirow[t]{2}{*}{ Oriental (4) } & 11. Plathymenia foliolosa Benth., ${ }^{2,6,16}$ & Generalista \\
\hline & $\begin{array}{l}\text { 12. Zygia latifolia var. glabrata (Mart.) } \\
\text { Barneby \& J.W. Grimes }{ }^{19}\end{array}$ & Generalista \\
\hline 3. Brasil & 13. Enterolobium gummiferum (Mart.) J.F. Macbr. ${ }^{9}$ & Generalista \\
\hline \multirow[t]{2}{*}{ Centro-Oriental (3) } & 14. Mimosa bimисronata (DC.) Kuntze var. bimucronata ${ }^{13,14}$ & ${ }^{14}$ Generalista \\
\hline & 15. Piptadenia gonoacantha (Mart.) v J.F. Macbr., ${ }^{2,5,16}$ & Generalista \\
\hline 4. Brasil Atlântico & 16. Pseudopiptadenia warmingii (Benth.) & Especialista \\
\hline \multirow[t]{3}{*}{ Nordeste-Sudeste-Sul (3) } & G.P. Lewis \& M.P. Lima²,17 & \\
\hline & $\begin{array}{l}\text { 17. Anadenanthera colubrina (Vell.) Brenan } \\
\text { var. colubrina } a^{2,8,21,22}\end{array}$ & Generalista \\
\hline & $\begin{array}{l}\text { 18. A. colubrina var. cebil (Griseb.) } \\
\text { Altschul } 1^{8,21,22}\end{array}$ & Generalista \\
\hline 5. Brasil Atlântico & 19. Enterolobium monjollo (Vell.) Mart. ${ }^{1,9}$ & Especialista \\
\hline \multirow[t]{4}{*}{ Nordeste-Sudeste (05) } & 20. Inga leptantha Benth..$^{2,11}$ & Especialista \\
\hline & 21. Parapiptadenia pterosperma (Benth.) Brenan ${ }^{2,15}$ & Especialista \\
\hline & $\begin{array}{l}\text { 22. Pseudopiptadenia contorta (DC.) } \\
\text { G.P.Lewis \& M.P.Lima }{ }^{2,17}\end{array}$ & Generalista \\
\hline & 23. Stryphnodendron polyphyllum Mart. ${ }^{2,6,18}$ & Generalista \\
\hline 6. Brasil Atlântico & 24. Abarema obovata (Benth.) Barneby \& J.W. Grimes ${ }^{1,2}$ & Especialista \\
\hline \multirow[t]{2}{*}{ Sudeste (3) } & 25. Inga cordistipula Mart. ${ }^{11}$ & Especialista \\
\hline & 26. Inga sp..$^{12}$ & Especialista \\
\hline
\end{tabular}

\footnotetext{
*Referências de distribuições geográficas e ocorrências em formações vegetacionais: ${ }^{1}$ Barneby \& Grimes (1996); ${ }^{2}$ Mendonça Filho (1996); ${ }^{3}$ Rico Arce (2001); ${ }^{4}$ Bentham (1876); ${ }^{5}$ Barroso (1965); ${ }^{6}$ Lewis (1987); ${ }^{7}$ Silva (1990); ${ }^{8}$ Altschul (1964); ${ }^{9}$ Mesquita (1990); ${ }^{10}$ Pennington (1997); ${ }^{11}$ Garcia (1998); ${ }^{12}$ Nunes (2003); ${ }^{13}$ Barneby (1991); ${ }^{14}$ Burkart (1979); ${ }^{15}$ Lima \& Lima (1984); ${ }^{16}$ Bentham (1875); ${ }^{17}$ Lewis \& Lima (1991); ${ }^{18}$ Martins (1981); ${ }^{19}$ Barneby \& Grimes (1997); ${ }^{20}$ Zarucchi (1993); ${ }^{21}$ Prado \& Gibbs (1993); ${ }^{22}$ Mendonça et al.(1998).
} 
em florestas semidecíduas montanas e submontanas (Oliveira-Filho \& Fontes 2000).

Albizia pedicellaris foi coletada no PERD às margens da Lagoa Dom Helvécio, no trecho sul. Está presente na América Central (Costa Rica) e ocorre de forma descontínua na América do Sul (Venezuela, Guianas, Brasil, Equador, Colômbia, Peru e Bolívia). No Brasil está distribuída nos estados do Amazonas, Maranhão e, disjuntamente, ao longo da costa sudeste brasileira, na Bahia, Rio de Janeiro e São Paulo (Barneby \& Grimes 1996).

No Parque, as espécies de Inga com distribuição neotropical foram encontradas em margens de estradas e trilhas ou no interior da floresta, sempre associadas a ambientes úmidos próximos às lagoas. A presença destas espécies com este padrão de distribuição sugere a migração de espécies através de florestas de galeria (Oliveira-Filho \& Ratter 1995).

Inga capitata está distribuída pela Américas Central (Costa Rica) e do Sul (Bolívia e Brasil) (Pennington 1997). No Brasil tem seu limite sul no estado de São Paulo, ocorrendo na floresta ombrófila aberta submontana da amazônia, na floresta estacional semidecídua no interior dos estados da Bahia e Minas Gerais e na floresta ombrófila densa de terras baixas, do litoral da Bahia a São Paulo (Garcia 1998). I. edulis ocorre na América do Sul, em toda a região tropical, com exceção das regiões áridas do Nordeste e Planalto Central do Brasil, que se estende até o Chaco na Argentina (Pennington 1997). I. marginata ocorre do sul do México até o norte da Argentina (Pennington 1997). Sua ocorrência em florestas estacionais é restrita às matas úmidas, não ocorrendo em meio às savanas estépicas (Garcia 1998). I. thibaudiana distribui-se pelo México, América Central e região tropical da América do Sul (Pennington 1997). No Brasil ocorre na floresta ombrófila densa de terras baixas que recobre a região dos tabuleiros do Espírito Santo e na Bahia, penetrando no continente através das florestas estacionais distribuídas pelas savanas do estado de Minas Gerais (Garcia 1998). Inga vera subsp. affinis é comum na América do Sul Tropical, da Colômbia até o Uruguai e com poucos registros na América Central (Pennington 1997). No Brasil suas populações ocupam tanto ambientes higrófilos, quanto aqueles mais áridos encontrados na Caatinga e no Cerrado, onde estão sempre associados à margem de rios perenes ou temporários (Garcia 1998).

Das espécies citadas para este padrão de distribuição, três encontram-se amplamente distribuídas no neotrópico chegando a alcançar o México: Acacia polyphylla (Rico Arce 2001), Inga marginata e I. thibaudiana (Pennington 1997).

2. Distribuição América do Sul Ocidental-Centro-Oriental (Tab. 2): Este padrão foi constatado em quatro táxons (15\%). $\mathrm{O}$ extremo mais ao norte da distribuição é a Guiana e o limite meridional está localizado nos estados do Paraná ou Santa Catarina. Albizia polycephala, Inga flagelliformis, Plathymenia foliolosa (Fig. 2) e Zygia latifolia var. glabrata, compõem este padrão. Todos eles considerados elementos florísticos generalistas. Albizia polycephala foi encontrada no PERD em ambientes abertos como margens de estrada e trilhas e também no interior da floresta em ambientes úmidos. Tem ocorrência registrada no Peru (Zarucchi 1993) e no Brasil, onde ocorre no leste do Brasil, de Pernambuco até o Rio de Janeiro (Barneby \& Grimes 1996), Paraná e Santa Catarina (Burkart 1979).

Inga flagelliformis ocorreu no subosque da floresta, no trecho sul do Parque. Encontrase distribuída ao longo do litoral do estado da Bahia até o Rio de Janeiro e suas populações penetram no continente pelas florestas estacionais do estado de Minas Gerais, cruzando as savanas até atingir seu limite norte, na Guiana (Garcia 1998).

Plathymenia foliolosa foi encontrada no PERD nos trechos sul e central, onde apresentou distribuição condensada em uma parte da estrada do Salão Dourado. Ocorre nos países da América do Sul como Paraguai, Bolívia (Burkart 1952; Burkart 1979) e Brasil (Lewis 1987), onde ocorre nos estados da Bahia, Piauí, Ceará, Goiás e Minas Gerais (Bentham 1875; Lewis 1987; Mendonça Filho 1996). 
Zygia latifolia var. glabrata foi coletada no Parque em áreas alagadas ou bastante úmidas, associadas a ambientes abertos como estradas e trilhas e também próxima a lagoas, somente no trecho central. Ocorre em florestas ripárias localizadas em baixas elevações, na floresta atlântica entre a região central da Bahia e leste do Rio de Janeiro, em Pernambuco e na região leste de Minas Gerais; está aparentemente disjunta ao longo do Rio Paraná, entre o leste do Paraguai e Paraná e em Ituiutaba no Triângulo Mineiro (Barneby \& Grimes 1997). Sua preferência de habitat evidencia as migrações via rede dendrítica de florestas de galeria propostas por Oliveira-Filho \& Ratter (1995), como evidenciado pelas espécies de Inga.

3. Brasil Centro-Oriental (Tab. 2): Padrão observado em três táxons (12\%) com distribuição no centro-oeste, no norte, nordeste, sudeste e/ou no sul do Brasil, com limite norte no estado do Pará e, sul, no estado do Rio Grande do Sul. Observou-se neste padrão, o predomínio de elementos florísticos generalistas como: Enterolobium gummiferum, Mimosa bimucronata var. bimucronata e Piptadenia gonoacantha (Fig. 3). Enterolobium gummiferum foi encontrada no interior da floresta somente no trecho sul do Parque. Está distribuída pelos estados de Minas Gerais, Bahia, Distrito Federal, Goiás, Maranhão, Mato Grosso, Mato Grosso do Sul, Pará, Piauí e São Paulo e foi considerada, por Mesquita (1990), restrita ao cerrado.

Mimosa bimucronata var. bimucronata foi coletada no PERD somente no trecho sul em locais brejosos ou inundáveis. Segundo Burkart (1979) esta variedade é heliófita e seletiva higrófila, muito abundante nas várzeas brejosas ao longo dos rios, banhados e outras depressões dos terrenos. Ocorre nas planícies litorâneas da costa atlântica desde Alagoas até o Rio Grande do Sul, estendendo-se para o interior do Brasil, ocorrendo no vale do baixo São Francisco, na Bahia; no Distrito Federal, Minas Gerais (alcançando $1.500 \mathrm{~m}$ na Serra do Espinhaço) e São Paulo (Barneby 1991).
Piptadenia gonoacantha, no PERD ocorre em ambientes úmidos e secos, no interior da floresta e nas margens de estradas, tanto do trecho sul quanto central. Ocorre do Piauí até São Paulo (Bentham 1875; Barroso 1965; Mendonça Filho 1996). Habita florestas de galeria no cerrado e floresta pluvial atlântica (Lorenzi, 1992; Mendonça et al. 1998).

\section{Brasil Atlântico Nordeste-} Sudeste-Sul (Tab. 2): Este padrão, observado em três táxons $(12 \%)$ é caracterizado pela faixa de distribuição desde o nordeste, principalmente a Bahia, até o sul do Brasil, em geral, o Paraná e/ou Santa Catarina. Estão incluídos neste padrão os elementos florísticos generalistas: Anadenanthera colubrina var. colubrina e A. colubrina var. cebil e especialista: Pseudopiptadenia warmingii (Fig. 3). P. warmingii foi coletada no parque somente no trecho central e ocorre em ambientes abertos às margens da estrada e no interior da floresta. É encontrada com frequiência em formações da floresta atlântica

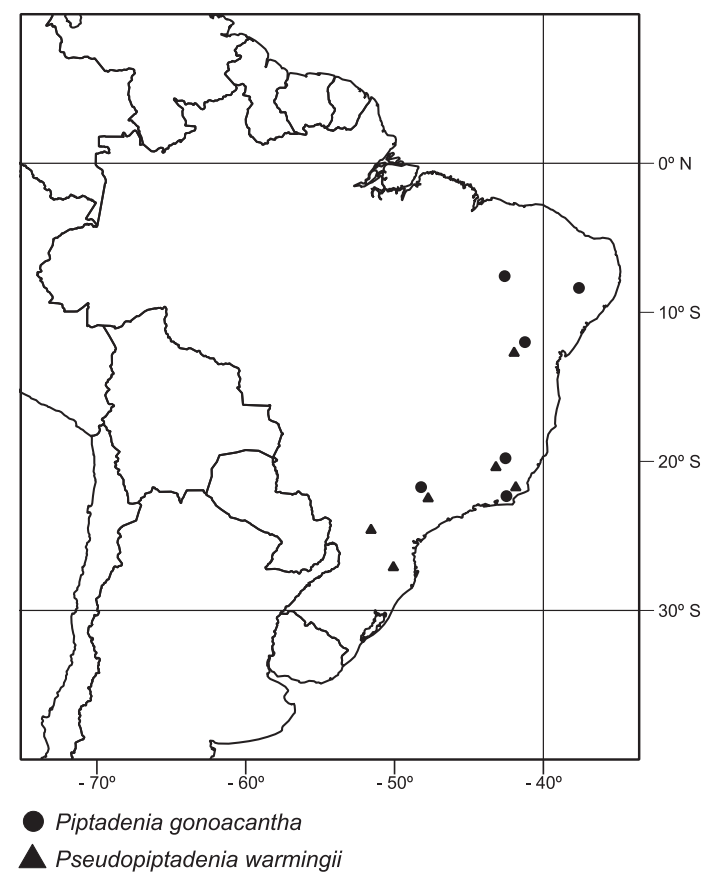

Figura 3 - Piptadenia gonoacantha: Distribuição Brasil Centro-Oriental; Pseudopiptadenia warmingii: Distribuição Brasil Atlântico Nordeste-Sudeste-Sul. 
da Bahia até Santa Catarina (Lewis \& Lima 1991; Mendonça Filho 1996).

Anadenanthera colubrina var. colubrina foi coletada no PERD nos trechos sul e central. Ocorre em ambientes úmidos e abertos como trilhas de acesso a lagoas e margens da Lagoa Dom Helvécio e também é registrada em áreas abertas e secas como margens de estradas, principalmente na estrada do Salão Dourado. Esta variedade está distribuída na Bahia (Nordeste), no Rio de Janeiro e São Paulo (Sudeste), no Paraná (Sul) e em Misiones, na Argentina (Altschul 1964; Prado \& Gibbs 1993).

Anadenanthera colubrina var. cebil ocorre no PERD principalmente em áreas abertas, às margens das estradas tanto do trecho sul quanto central. Distribui-se simpatricamente com a variedade típica nas áreas de caatinga da Bahia e também em Misiones (Argentina) e de forma alopátrica nos estados do Rio de Janeiro e nas florestas do planalto de São Paulo e Paraná (Prado \& Gibbs 1993). Segundo Altschul (1964), pode ser encontrada na Argentina, Bolívia, Brasil, Paraguai e Peru.

\section{Brasil Atlântico Nordeste-Sudeste}

(Tab. 2): Padrão encontrado em cinco espécies (19\%): Enterolobium monjollo, Inga leptantha (Fig. 4) e Parapiptadenia pterosperma, considerados elementos florísticos especialistas e Pseudopiptadenia contorta e Stryphnodendron polyphyllum, elementos florísticos generalistas.

Enterolobium monjollo no Parque foi registrado somente nas margens da estrada do Salão Dourado no trecho central. Esta espécie ocorre na floresta atlântica, desde a Bahia até o Rio de Janeiro (Barneby \& Grimes 1996). Segundo Mesquita (1990) sua distribuição é restrita principalmente ao sudeste brasileiro, onde foi registrada com maior freqüência para o Vale do Ribeira (SP), Rio de Janeiro, Espírito Santo e Minas Gerais.

Inga leptantha, ocorreu no PERD, no subosque da floresta nos trechos sul e central em ambientes úmidos próximos a lagoas.

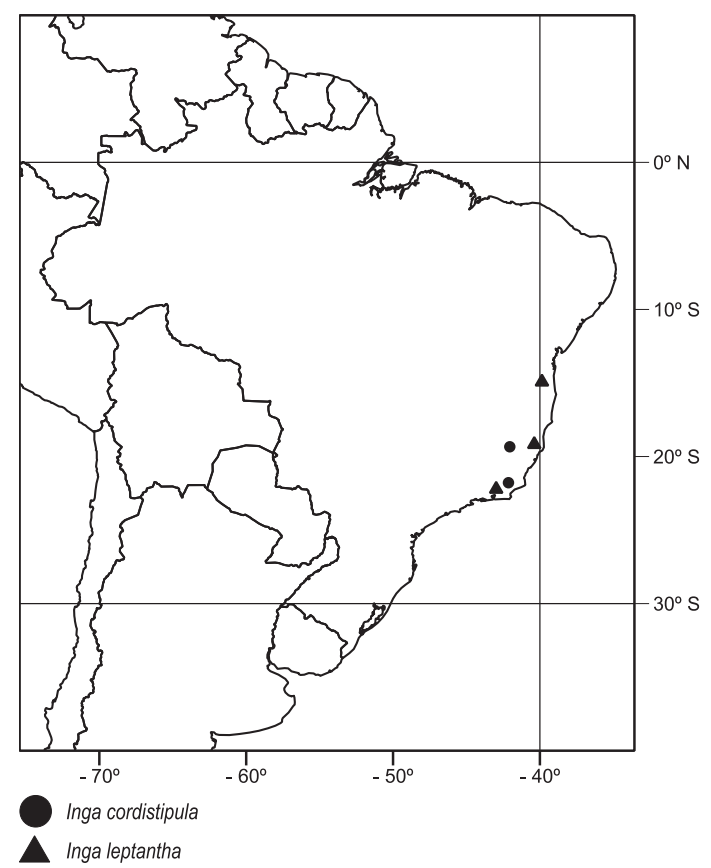

Figura 4 - Inga leptantha: Distribuição Brasil Atlântico Nordeste-Sudeste; Inga cordistipula: Distribuição Brasil Atlântico Sudeste.

Ocorre da Bahia ao Rio de Janeiro (Mendonça Filho 1996; Garcia 1998).

Parapiptadenia pterosperma no Parque foi coletada no interior da floresta nos trechos central e sul. Ocorre da Bahia ao Rio de Janeiro (Lima \& Lima 1984; Mendonça Filho 1996). De acordo com Lima \& Lima (1984) está presente nas margens altas próximas às nascentes do rio Doce, em Minas Gerais.

Pseudopiptadenia contorta ocorre no Parque em ambientes abertos às margens de estradas e no interior da floresta, em ambientes secos e úmidos como margens de lagoas. Tem ocorrência registrada da Paraíba até São Paulo, em formações da floresta atlântica e caatinga (Lewis \& Lima 1991; Mendonça Filho 1996).

Stryphnodendron polyphyllum no PERD é registrada tanto nas margens de estradas quanto no interior da floresta em ambientes úmidos, nos trechos sul e central. Ocorre na Bahia (cerrado e campos rupestres), Minas Gerais e Rio de Janeiro (floresta estacional semidecídua e floresta ombrófila densa) e Pernambuco (Martins 
1974; Martins 1981; Lewis 1987; Mendonça Filho 1996).

6. Brasil Atlântico Sudeste (Tab. 2): É a faixa de distribuição de três espécies (12\%) consideradas elementos florísticos especialistas: Abarema obovata, Inga cordistipula (Fig. 4) e Inga sp.

Abarema obovata foi encontrada no Parque no trecho central, próxima à Lagoa do Meio em local inundável. Segundo Barneby \& Grimes (1996), ocorre nas matas de encosta e algumas vezes sobre a mata de cipó, em altitudes que variam entre 400-1030 m. Em Minas Gerais ocorre sobre as encostas da serra do Espinhaço, em Grão Mogol, na região de Belo Horizonte e em Viçosa (Barneby \& Grimes 1996).

Inga cordistipula no PERD ocorre no interior da floresta nos trechos sul e central. Segundo Garcia (1998) sua ocorrência é restrita ao estado do Rio de Janeiro e à Zona da Mata de Minas Gerais.

Inga sp. foi encontrada no interior da floresta, no trecho central do Parque e, provavelmente, é uma espécie nova para a ciência sendo, até o momento, endêmica do PERD.

\section{Similaridades florísticas}

Três espécies ocorreram na maioria das áreas comparadas (Tab. 3): Piptadenia gonoacantha, em oito áreas enquanto que Pseudopiptadenia contorta e Albizia polycephala em sete áreas. Todas são consideradas elementos florísticos generalistas (Tab. 2). Piptadenia gonoacantha apresenta ampla distribuição, ocorrendo na Região Sudeste do Brasil, em floresta estacional, entre 500-700 $\mathrm{m}$ de altitude e em áreas em regeneração (Lorenzi 1992). Pseudopiptadenia contorta ocorre em ambientes do domínio da caatinga arbórea, em matas de restinga e nas formações do domínio florestal atlântico (Lewis \& Lima 1989). Embora Albizia polycephala tenha sido encontrada no PERD, não foi registrada por Barneby \& Grimes (1996) para Minas Gerais. Entretanto, Mendonça-Filho (1996) listou esta espécie para a RPPN Feliciano Miguel Abdala.

As espécies que ocorreram somente no PERD, dentre as áreas comparadas, foram:
Enterolobium gummiferum e Inga cordistipula. A primeira espécie foi considerada um elemento florístico generalista e a segunda especialista (Tab. 2). E. gummiferum embora apresente ampla distribuição geográficaé considerada por Mesquita (1990) de ocorrência restrita à vegetação de cerrado. A presença de I. cordistipula no PERD, ampliou sua área de distribuição, antes restrita ao estado do Rio de Janeiro e Zona da Mata de Minas Gerais (Garcia 1998).

As três localidades com o maior número de espécies (Tab. 3) são o PERD, CVRD e a RPPN Feliciano Miguel Abdala (RBC), com 25, 24 e 20 espécies, respectivamente. Lombardi \& Gonçalves (2000), estudando a composição florística do PERD e da RBC mostraram que a primeira área teve o número de espécies de Mimosoideae (16) inferior em relação à segunda (28), embora o PERD apresente uma área territorial bem maior que a RBC (Tab. 3). Portanto, a maior riqueza em número de espécies observada para o PERD e para a CVRD, neste trabalho, não parece estar relacionada ao tamanho da área, mas sim, ao esforço amostral.

Essas três áreas apresentaram nove espécies em comum: Acacia polyphylla, Albizia polycephala, Inga capitata, I. edulis, I. flagelliformis, I. leptantha, I. thibaudiana, Parapiptadenia pterosperma e Pseudopiptadenia contorta (Tab. 3). Destas, somente Inga leptantha e Parapiptadenia pterosperma são consideradas elementos florísticos especialistas (Tab. 2).

A análise de agrupamento das áreas estudadas com base nas espécies de Mimosoideae (Fig. 5) revelou dois blocos ao nível de 0,22 da escala de Sorensen, que são:

- Bloco A: UFV, ESAL, MCAR, CFRI, CVRD, RBC e PERD.

- Bloco B: ITAT, PEFI, MCIM.

O Bloco A reuniu formações vegetacionais dos estados de Minas Gerais (UFV, ESAL, RBC e PERD), Espírito Santo (CVRD) e Rio de Janeiro (MCAR e CFR) que são: floresta estacional semidecídua montana e submontana, floresta estacional semidecídua de terras baixas e floresta ombrófila densa das terras baixas. 
Tabela 3 - Levantamentos florísticos de Mimosoideae arbóreas utillizados neste trabalho. GE.: Gêneros; ESP.: Espécies; TAM.: Tamanho da área; ALT.: Altitude; CLI.: Clima (Sistema de Köppen); AMOST.: Tipo de amostragem realizada: I: Inventário e estudo taxonômico de Leguminosae; II: Inventário de Leguminosae a partir de levantamento de herbário; III: Inventário de Leguminosae a partir de levantamento bibliográfico e estudo de coleções botânicas; IV: Inventário florístico e fitossociológico; V: Inventário e estudo taxonômico de Mimosoideae (Leguminosae).

\begin{tabular}{|c|c|c|c|c|c|c|c|c|}
\hline LOCAL & GE. & ESP. & VEGETAÇÃO & $\begin{array}{l}\text { TAM. } \\
\text { (ha) }\end{array}$ & $\begin{array}{l}\text { ALT. } \\
(\mathbf{m} .)\end{array}$ & CLI. & AMOST. & AUTORES \\
\hline $\begin{array}{l}(\mathbf{R B C}) \mathrm{RPPN} \\
\text { Feliciano } \\
\text { Miguel } \\
\text { Abdala, MG }\end{array}$ & 11 & 20 & $\begin{array}{l}\text { Floresta Estacional } \\
\text { Semidecídua } \\
\text { Submontana }\end{array}$ & 880 & $318-628$ & Aw & $\mathrm{I}$ & $\begin{array}{l}\text { 1.Mendonça Filho } \\
\text { (1996) }\end{array}$ \\
\hline $\begin{array}{l}\text { (PEFI) Parque } \\
\text { Estadual } \\
\text { das Fontes } \\
\text { do Ipiranga, SP }\end{array}$ & 5 & 9 & $\begin{array}{l}\text { Floresta Estacional } \\
\text { Semidecídua } \\
\text { Montana }\end{array}$ & 549,31 & 798 & Cwb & I & $\begin{array}{l}\text { 2.Custódio Filho } \\
\text { \&Mantovani (1986) }\end{array}$ \\
\hline $\begin{array}{l}\text { (CVRD) } \\
\text { Reserva } \\
\text { Florestal de } \\
\text { Linhares, ES }\end{array}$ & 11 & 24 & $\begin{array}{l}\text { Floresta Ombrófila } \\
\text { Densa das } \\
\text { Terras Baixas }\end{array}$ & 22.000 & $28-65$ & Awi & II & $\begin{array}{l}\text { 3.Jesus \& Garcia } \\
\text { (1992) }\end{array}$ \\
\hline $\begin{array}{l}\text { (MCAR) Mata } \\
\text { do Carvão, RJ }\end{array}$ & 10 & 12 & $\begin{array}{l}\text { Floresta Ombrófila } \\
\text { Densa das Terras } \\
\text { Baixas }\end{array}$ & 1.053 & $15-50$ & Aw & III & 4.Lima(2000) \\
\hline $\begin{array}{l}\text { (ITAT) PARNA } \\
\text { Itatiaia, RJ }\end{array}$ & 8 & 16 & $\begin{array}{l}\text { Floresta Ombrófila } \\
\text { Densa Alto-Montana }\end{array}$ & 30.000 & $390-2.787$ & $\mathrm{Cw}$ & III & 5.Lima $(2000)$ \\
\hline $\begin{array}{l}\text { (CFRI) Cabo } \\
\text { Frio, RJ }\end{array}$ & 7 & 10 & $\begin{array}{l}\text { Floresta Estacional } \\
\text { Semidecídua das } \\
\text { Terras Baixas }\end{array}$ & 7.500 & $4-100$ & Aw & III & 6.Lima $(2000)$ \\
\hline $\begin{array}{l}\text { (MCIM) Macaé } \\
\text { de Cima, RJ }\end{array}$ & 4 & 14 & $\begin{array}{l}\text { Floresta Ombrófila } \\
\text { Densa Montana }\end{array}$ & 7.200 & $880-1720$ & $\mathrm{Cfb}$ & IV & $\begin{array}{l}\text { 7.Lima \& Guedes- } \\
\text { Bruni (1997) }\end{array}$ \\
\hline $\begin{array}{l}\text { (ESAL) Reserva } \\
\text { Florestal da } \\
\text { ESAL, Lavras, MG }\end{array}$ & 6 & 6 & $\begin{array}{l}\text { Floresta Estacional } \\
\text { Semidecídua } \\
\text { Montana }\end{array}$ & 5.8 & 925 & Cwb & IV & $\begin{array}{l}\text { 8.Oliveira-Filho et al. } \\
\text { (1994) }\end{array}$ \\
\hline $\begin{array}{l}\text { (UFV) Floresta } \\
\text { do Jardim } \\
\text { Botânico } \\
\text { da UFV, } \\
\text { Viçosa, MG }\end{array}$ & 7 & 9 & $\begin{array}{l}\text { Floresta Estacional } \\
\text { Semidecídua } \\
\text { Submontana }\end{array}$ & 75 & 700 & Cwa & IV & 9.Sevilha et al. (2001) \\
\hline $\begin{array}{l}\text { (PERD) Parque } \\
\text { Estadual do } \\
\text { Rio Doce, } \mathrm{MG}\end{array}$ & 14 & 25 & $\begin{array}{l}\text { Floresta Estacional } \\
\text { Semidecídua } \\
\text { Submontana }\end{array}$ & 35.974 & $250-380$ & Aw & $\mathrm{V}$ & 10.Nunes(2003) \\
\hline
\end{tabular}


Tabela 4-Matriz de similaridade florística entre as regiões de Floresta Atlântica, calculada a partir do índice de Sorensen. As siglas correspondem às localidades apresentadas na Tabela 3.

\begin{tabular}{|c|c|c|c|c|c|c|c|c|c|c|}
\hline \multirow{2}{*}{$\overline{\text { PERD }}$} & \multirow{2}{*}{$\begin{array}{l}\text { PERD } \\
1\end{array}$} & \multirow{2}{*}{ ESAL } & \multirow[t]{2}{*}{ UFV } & \multirow[t]{2}{*}{$\mathrm{RBC}$} & \multirow[t]{2}{*}{ CVRD } & \multirow[t]{2}{*}{ CFRI } & \multicolumn{2}{|c|}{ MCAR ITAT } & \multicolumn{2}{|c|}{ MCIM PEFI } \\
\hline & & & & & & & & & & \\
\hline ESAL & 0,258 & 1 & & & & & & & & \\
\hline UFV & 0,424 & 0,428 & 1 & & & & & & & \\
\hline $\mathrm{RBC}$ & 0,800 & 0,230 & 0,428 & 1 & & & & & & \\
\hline CVRD & 0,458 & 0,069 & 0,193 & 0,418 & 1 & & & & & \\
\hline CFRI & 0,285 & 0,125 & 0,222 & 0,266 & 0,303 & 1 & & & & \\
\hline MCAR & 0,432 & 0,333 & 0,400 & 0,375 & 0,342 & 0,545 & 1 & & & \\
\hline ITAT & 0,341 & 0,363 & 0,333 & 0,333 & 0,102 & 0,153 & 0,285 & 1 & & \\
\hline MCIM & 0,205 & 0,100 & 0,090 & 0,235 & 0,216 & 0,166 & 0,076 & 0,333 & 1 & \\
\hline PEFI & 0,294 & 0,266 & 0,352 & 0,206 & 0,062 & 0,315 & 0,190 & 0,400 & 0,347 & 1 \\
\hline
\end{tabular}

O Bloco B reuniu formações vegetacionais dos estados do Rio de Janeiro (ITAT e MCIM) e São Paulo (PEFI), que são: Floresta Ombrófila Densa Alto-Montana e Montana e a Floresta Estacional Semidecídua Montana.

O Parque Estadual do Rio Doce (PERD) e a RPPN Feliciano Miguel Abdala (RBC), foram as áreas que apresentaram a flora mais semelhante, formando um grupo ao nível de 0,80 da escada de Sorensen (Tab. 4), ambos localizados na região leste de Minas Gerais, porção média da Bacia do Rio Doce e com tipologia de floresta estacional semidecídua submontana (Veloso et al. 1991). A metodologia empregada nos inventários realizados nestas áreas (Tab. 3) e a especificidade em enfocar somente o grupo Leguminosae podem ter influenciado este resultado. Entretanto a presença de mesma tipologia florestal, a proximidade entre as áreas e a localização na mesma bacia hidrográfica podem justificar esta semelhança. Estas áreas apresentaram em comum as seguintes espécies: Abarema obovata, Acacia polyphylla, Albizia polycephala, Anadenanthera colubrina, A. peregrina, Enterolobium monjollo, Inga capitata, I. edulis, I. flagelliformis, I. leptantha, I. marginata, I. thibaudiana, Parapiptadenia pterosperma, Piptadenia gonoacantha, Plathymenia foliolosa, Pseudopiptadenia contorta, P. warmingii e Stryphnodendron polyphyllum. Das espécies citadas, apenas
Abarema obovata foi registrada somente nestas duas áreas. Segundo Barneby e Grimes (1996) esta espécie pode ocorrer em matas de encosta e algumas vezes sobre a mata de cipó, em altitudes que variam entre 400-1030 m.

Esse grupo se juntou a CVRD ao nível de 0,43 da escala de Sorensen (Tab. 4), que está localizada na cidade de Linhares, norte do Espírito Santo, na porção baixa da Bacia do Rio Doce, com vegetação de floresta ombrófila densa de terras baixas. As espécies comuns entre essas três áreas foram: Acacia polyphylla, Albizia polycephala, Inga capitata, I. edulis, I. flagelliformis, I. leptantha, I. thibaudiana, Parapiptadenia pterosperma e Pseudopiptadenia contorta. Dessas, três são de ocorrência restrita para essas localidades: Inga edulis, I. flagelliformis e I. thibaudiana. Essas três espécies de Inga ocorrem tanto em florestas ombrófilas quanto em florestas estacionais (Garcia 1998). Zygia latifolia var. glabrata, táxon restrito às florestas ripárias (Barneby \& Grimes 1997), foi de ocorrência exclusiva para o PERD e CVRD. O tipo de dispersão hidrocórica pode explicar a migração desta espécie via rede dendrítica de florestas de galeria, padrão proposto por Oliveira-Filho \& Ratter (1995). A similaridade florística entre as florestas semidecíduas de interior e aquelas de terras baixas, dentro da Bacia do Rio Doce também foi demonstrada por Oliveira-Filho \& 
Fontes (2000) que atribuíram este fato à migração de espécies das formações semidecíduas de terras baixas em direção às de interior.

$\mathrm{O}$ terceiro grupo reuniu a área de Cabo Frio com a área denominada Mata do Carvão, localizada na região norte fluminense. A primeira com ocorrência de floresta estacional semidecídua de terras baixas (Veloso et al. 1991) e a segunda com floresta ombrófila densa das terras baixas (Veloso et al. 1991). Esse grupo foi isolado ao nível de 0,54 da escala de Sorensen (Tab. 4) e apresentou em comum as seguintes espécies: Albizia polycephala, Chloroleucon tortum, Inga laurina, Mimosa bimucronata, Parapiptadenia pterosperma e Pseudopiptadenia contorta. Espécies consideradas elementos generalistas como Albizia polycephala, Mimosa bimucronata e Pseudopiptadenia contorta e especialista como Parapiptadenia pterosperma foram compartilhadas com o PERD. A similaridade florística existente entre o PERD e estas áreas parece estar associadas às baixas altitudes em que se encontram. Albizia pedicellaris foi compartilhada somente entre a Mata do Carvão, PERD e CVRD, com distribuição na floresta atlântica de terras baixas (Barneby \& Grimes 1996) e no PERD sendo encontrada em ambiente ripário.

O quarto grupo reuniu a área da Reserva Florestal da ESAL, localizada no município de Lavras, sul do estado de Minas Gerais, com tipologia de Floresta Estacional Semidecídua Montana (Veloso et al. 1991) com a área denominada Jardim Botânico da UFV, localizado no município de Viçosa, Zona da Mata de Minas Gerais e tipologia de floresta estacional semidecídua submontana (Veloso et al. 1991). Esse grupo foi isolado, ao nível de 0,42 da escala de Sorensen (Tab. 4) e apresentou em comum as seguintes espécies: Albizia polycephala, Inga vera subsp. affinis e Piptadenia gonoacantha. Nenhuma delas de ocorrência restrita para essas duas localidades e todas três compartilhadas com o PERD. As baixas similaridades encontradas entre o PERD e a ESAL, 0,25 e PERD e UFV, 0,42 da escala de Sorensen, parecem ter sido influenciadas pela diferença altitudinal entre as duas últimas áreas em relação à primeira (Tab. 3). A importância da altitude na diferenciação florística de florestas estacionais foi relatada para estas formações na Região Sudeste do Brasil (Oliveira-Filho et al. 1994a).

O quinto grupo reuniu a área de Itatiaia, localizada na região do Médio Paraíba, sobre as elevações da Serra da Mantiqueira, no maciço do Itatiaia (Lima 2000), com tipologia de floresta ombrófila densa alto-montana (Veloso et al. 1991) com a área do Parque Estadual das Fontes do Ipiranga (PEFI), localizado na zona sudeste do município de São Paulo (Rocha \& Cavalheiro 2001) com tipologia de floresta estacional semidecídua montana (Veloso et al. 1991). Esse grupo foi isolado ao nível de 0,40 da escala de Sorensen (Tab. 4), ou seja, com baixa similaridade. Adiferença entre o esforço de coleta e a metodologia empregados nos inventários analisados nesta comparação (Tab. 3), podem estar influenciando a baixa similaridade encontrada, embora ambos tenham enfocado apenas as Leguminosae das referidas regiões. Estas áreas apresentaram as seguintes espécies em comum: Abarema langsdorfii, Anadenanthera colubrina, Inga sessilis, I. vera e Piptadenia gonoacantha. Todas com ocorrência registrada em formações montanas (Morim 2006). Somente Abarema langsdorfii e Inga sessilis não foram compartilhadas com o PERD. A baixa similaridade florística encontrada entre o PERD e o PEFI, 0,29 da escala de Sorensen, ambos com o mesmo tipo de formação florestal, pode estar relacionada a dois fatores: à maior distância do oceano em que se encontra o PERD e à maior altitude encontrada no PEFI (Tab. 3). Segundo Oliveira-Filho e Fontes (2000) o primeiro fator está relacionado com o aumento de duração da estação seca e o segundo às variações de temperaturas; podendo ser responsáveis pelas diferenças entre as floras de florestas semidecíduas. Também houve uma baixa similaridade entre a o PERD e Itatiaia, 0,34 da escala de Sorensen. O principal fator que parece ter atuado nesta dissimilaridade foi a elevada altitude encontrada em Itatiaia (Tab. 3).

O quinto grupo (Itatiaia e PEFI) ligou-se à área denominada Reserva Ecológica de Macaé 
de Cima, localizada no distrito de Macaé de Cima, município de Nova Friburgo, Rio de Janeiro (Lima 2000), com tipologia de floresta ombrófila densa montana. Esse grupo foi isolado, ao nível de 0,40 da escala de Sorensen (Tab. 4), também com baixa similaridade. As espécies responsáveis pela similaridade entre essas áreas foram: Abarema langsdorfii, Inga sessilis e Piptadenia gonoacantha. Esta última foi a única espécie compartilhada com o PERD e apresenta ocorrência registrada em formação montana na faixa de 600 a $900 \mathrm{~m}$ de altitude, no interior da mata e em locais de vegetação alterada (Morim 2006).

Observando o dendrograma (Fig. 5) e analisando os grupos, podemos verificar que as formações florestais localizadas nas regiões mais baixas isolaram-se daquelas localizadas nas regiões mais altas. A presença de um período de baixas temperaturas nas florestas montanas pode estar diferenciando as duas floras nessas formações. Fato também observado por Oliveira-Filho et al. (1994a) quando analisaram 30 áreas florestais da costa em direção ao interior do Brasil.

A presença de algumas espécies, somente nas áreas com altitudes elevadas, em florestas de planícies e pequenas elevações costeiras ou em baixas altitudes, como vales de bacias hidrográficas, provavelmente estão relacionadas à preferência de habitat de algumas espécies, determinando uma singularidade florística para essas áreas em função das restrições climáticas e edáficas a que estão submetidas.

A composição florística do PERD mostrouse semelhante às de outras formações florestais do sudeste analisadas nesse trabalho, não apresentando variações que possam indicar claramente uma origem distinta, corroborando a idéia da flora arbórea da floresta semidecídua ser um sub-conjunto da flora das florestas ombrófilas, proposta por Oliveira-Filho \& Fontes (2000).

Os padrões predominantes de distribuição geográfica dos táxons foram o Neotropical (30\%), seguido do Brasil Atlântico Nordeste-Sudeste (19\%). As espécies generalistas apresentaram principalmente o padrão de distribuição Neotropical (8 spp.) e as especialistas do domínio Attântico predominantemente os padrões Brasil Atlântico Nordeste-Sudeste (3 spp.) e Brasil Atlântico Sudeste (3 spp.), ocupando tanto as formações estacionais semidecíduas quanto as ombrófilas densas, indicando uma similaridade florística entre estas duas formações.

Os resultados indicaram uma ligação florística entre a floresta estacional semidecídua do PERD e as outras formações de floresta atlântica analisadas. Entretanto estudos de padrões de variação, riqueza e diversidade tanto de Leguminosae quanto de outras famílias, associados aos prováveis fatores ecológicos e históricos a que foram e ainda estão sendo submetidos, deverão ser realizados em outros remanescentes florestais do médio Rio Doce. Isto conduzirá a conclusões mais consistentes sobre as relações florísticas das formações florestais atlânticas interioranas do leste de Minas Gerais e outras encontradas na Região Sudeste do Brasil. Além disto, estes estudos também irão contribuir no desenvolvimento de planos de conservação da biodiversidade para a flora local, uma vez que é significativa a perda de biodiversidade nesta região, tanto como resultado

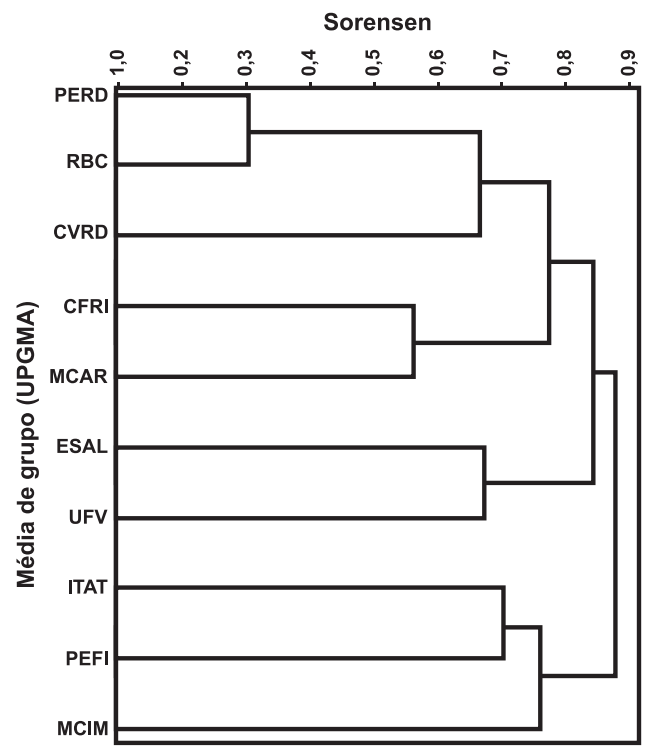

Figura 5 - Dendrograma apresentando similaridade florística entre as regiões de floresta atlântica dos estados do Espírito Santo, Rio de Janeiro, São Paulo e Minas Gerais, onde ocorrem espécies de Mimosoideae, utilizando como coeficiente o índice Sorensen e agrupando as localizades pelo método de média de grupo (UPGMA). As siglas correspondem às localidades apresentadas na Tabela 3. 
Tabela 5 - Matriz de presença (1) e ausência (0) das espécies arbóreas de Mimosoideae ocorrentes na Floresta Atlântica dos estados do Espírito Santo, Rio de Janeiro, São Paulo e Minas Gerais.

\begin{tabular}{|c|c|c|c|c|c|c|c|c|c|c|}
\hline Espécies & PERD & ESAL & UFV & $\mathbf{R B C}$ & CVRD & CFRIO & MCAR & ITAT & MCIMA & PEFI \\
\hline Abarema cochliocarpos (Gomes) Barneby \& J.W. Grimes & 0 & 0 & 0 & 0 & 1 & 0 & 0 & 0 & 0 & 0 \\
\hline Abarema filamentosa (Benth.) Pittier & 0 & 0 & 0 & 0 & 1 & 0 & 0 & 0 & 0 & 0 \\
\hline Abarema langsdorfii (Benth.) Barneby \& J.W. Grimes & 0 & 0 & 0 & 0 & 0 & 1 & 0 & 1 & 1 & 1 \\
\hline Abarema obovata (Benth.) Barneby \& J.W. Grimes & 1 & 0 & 0 & 1 & 0 & 0 & 0 & 0 & 0 & 0 \\
\hline Acacia polyphylla DC. & 1 & 0 & 1 & 1 & 1 & 0 & 1 & 0 & 0 & 0 \\
\hline Affonsea densiflora Benth. & 0 & 0 & 0 & 1 & 0 & 0 & 0 & 0 & 0 & 0 \\
\hline Albizia pedicellaris (DC.) L. Rico & 1 & 0 & 0 & 0 & 1 & 0 & 1 & 0 & 0 & 0 \\
\hline Albizia polycephala (Benth.) Killip & 1 & 1 & 1 & 1 & 1 & 1 & 1 & 0 & 0 & 0 \\
\hline Anadenanthera colubrina (Vell.) Brenan & 1 & 0 & 1 & 1 & 0 & 0 & 0 & 1 & 0 & 1 \\
\hline Anadenanthera peregrina (L.) Speg. & 1 & 1 & 0 & 1 & 0 & 0 & 1 & 1 & 0 & 0 \\
\hline Chloroleucon tortum (Mart.) Pittier & 0 & 0 & 0 & 0 & 0 & 1 & 1 & 0 & 0 & 0 \\
\hline Enterolobium contortisiliquum (Vell.) Morong. & 0 & 0 & 0 & 0 & 0 & 0 & 0 & 1 & 0 & 0 \\
\hline Enterolobium glaziovii (Benth.) Mesquita & 0 & 0 & 0 & 0 & 1 & 0 & 0 & 0 & 0 & 0 \\
\hline Enterolobium gummiferum (Mart.) J.F. Macbr. & 1 & 0 & 0 & 0 & 0 & 0 & 0 & 0 & 0 & 0 \\
\hline Enterolobium monjollo (Vell.) Mart. & 1 & 0 & 0 & 1 & 0 & 0 & 0 & 0 & 0 & 0 \\
\hline Inga alba (Sw.) Willd. & 0 & 0 & 1 & 0 & 0 & 0 & 0 & 0 & 0 & 0 \\
\hline Inga barbata Benth. & 0 & 0 & 0 & 0 & 0 & 0 & 0 & 1 & 1 & 0 \\
\hline Inga bullata Benth. & 0 & 0 & 0 & 0 & 0 & 0 & 1 & 0 & 0 & 0 \\
\hline Inga cabelo T.D. Penn. & 0 & 0 & 0 & 0 & 1 & 0 & 0 & 0 & 0 & 0 \\
\hline Inga capitata Desv. & 1 & 0 & 0 & 1 & 1 & 1 & 0 & 0 & 1 & 1 \\
\hline Inga cylindrica (Vell.) Mart. & 0 & 0 & 0 & 0 & 1 & 0 & 0 & 0 & 1 & 0 \\
\hline Inga cordistipula Mart. & 1 & 0 & 0 & 0 & 0 & 0 & 0 & 0 & 0 & 0 \\
\hline Inga edulis Mart. & 1 & 0 & 0 & 1 & 1 & 0 & 0 & 0 & 0 & 0 \\
\hline Inga exfoliata T.D. Penn. \& F.C.P. Garcia & 0 & 0 & 0 & 0 & 1 & 0 & 0 & 0 & 0 & 0 \\
\hline Inga flagelliformis (Vell.) Mart. & 1 & 0 & 0 & 1 & 1 & 0 & 0 & 0 & 0 & 0 \\
\hline Inga hispida Benth. & 0 & 0 & 0 & 0 & 1 & 0 & 0 & 0 & 0 & 0 \\
\hline Inga lanceifolia Benth. & 0 & 0 & 0 & 0 & 1 & 0 & 0 & 0 & 1 & 0 \\
\hline Inga laurina (Sw.) Willd. & 0 & 0 & 0 & 0 & 0 & 1 & 1 & 0 & 0 & 0 \\
\hline Inga lenticellata Benth. & 0 & 0 & 0 & 0 & 0 & 0 & 0 & 0 & 1 & 0 \\
\hline Inga lentiscifolia Benth. & 0 & 0 & 0 & 0 & 0 & 0 & 0 & 0 & 1 & 0 \\
\hline
\end{tabular}




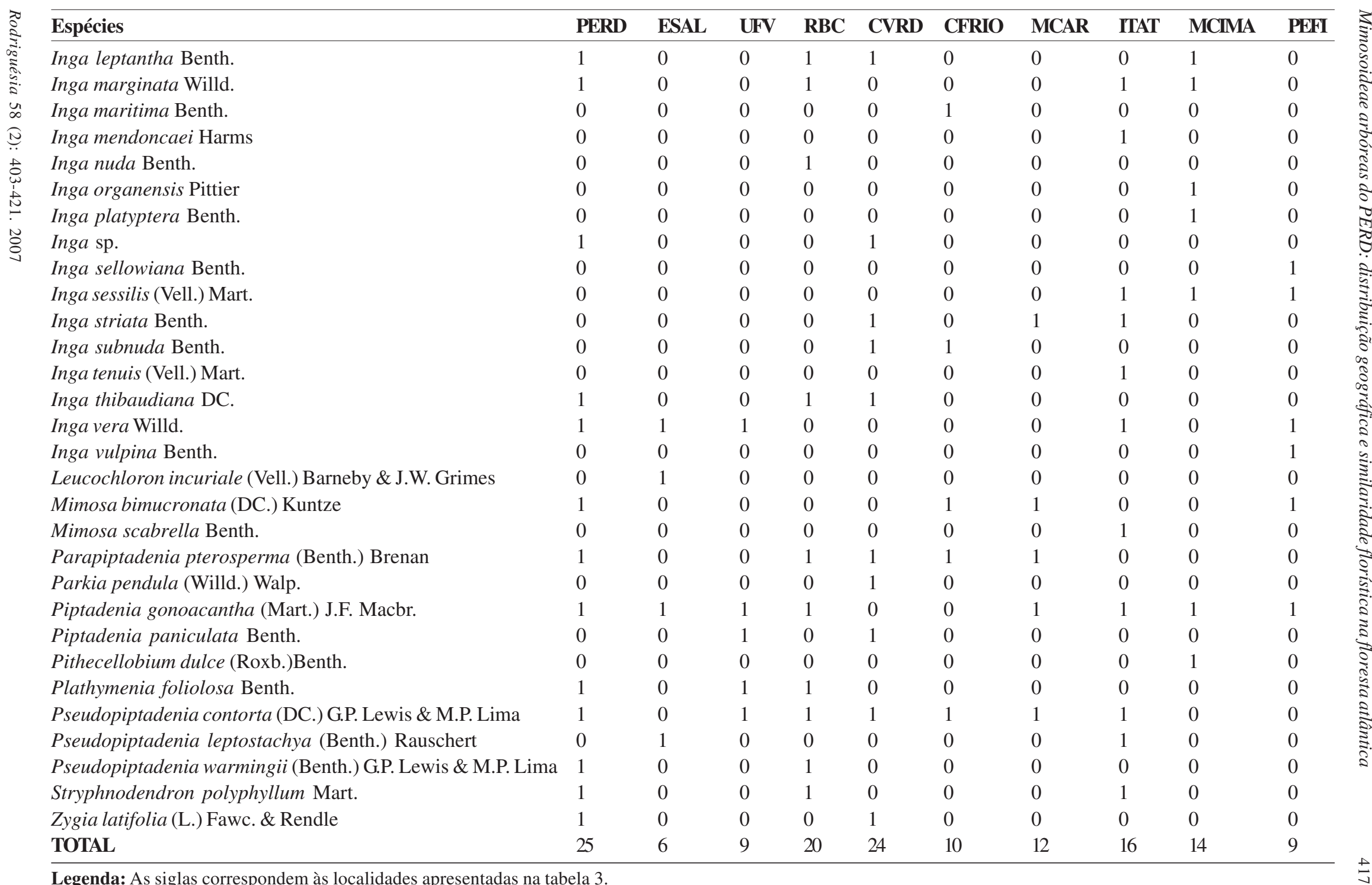

Legenda: As siglas correspondem às localidades apresentadas na tabela 3. 
do processo de fragmentação como pela supressão direta da vegetação e sua substituição por diferentes formas de uso do solo.

\section{Agradecimentos}

Os autores agradecem ao Departamento de Biologia Vegetal da UFV, pela infra-estrutura concedida para o desenvolvimento desse trabalho, à Fundação Geraldo Perlingeiro de Abreu/Unileste-MG pela concessão da bolsa de mestrado para a primeira autora e ao Instituto Estadual de Florestas de Minas Gerais pela autorização de coleta e apoio no trabalho de campo desenvolvido no Parque Estadual do Rio Doce.

\section{REFERÊNCIAS BIBLIGRÁFICAS}

Altschul, S. von R. 1964. A taxonomic study of the genus Anadenanthera. Contributions from the Gray Herbarium of Harvard University 193: 1-65.

Barneby, R. C. 1991. Sensitivae Censitae. A description of the genus Mimosa Linnaeus (Mimosaceae). New World. Memoirs of the New York Botanical Garden 65: 1-835.

Barneby, R. C. \& Grimes, J. W. 1996. Silk tree, Guanacaste, Monkey's Earring: A generic system for the Synandrous Mimosaceae of the Americas. Part I. Abarema, Albizia, and Allies. Memoirs of the New York Botanical Garden 74(1): 1- 292.

Barneby, R. C. \& Grimes, J. W. 1997. Silk tree, Guanacaste, Monkey's Earring: A generic system for the Synandrous Mimosaceae of the Americas. Memoirs of the New York Botanical Garden 74(2): 60-131.

Barroso, G. M. 1965. Leguminosas da Guanabara. Arquivos do Jardim Botânico do Rio de Janeiro 18: 115-118.

Barroso, G. M.; Peixoto, A. L.; Costa, C. G.; Ichaso, C. L. F.; Guimarães, E. F .\& Lima, H. C. 1991. Leguminosae. In: Sistemática de angiospermas do Brasil. Vol.2. Universidade Federal de Viçosa, Viçosa. Pp. 15-100.

Bentham, G. 1875. Revision of suborder Mimoseae. Transactions of the Linnean Society of London 30(3): 335-632.
Bentham, G. 1876. Leguminosae Mimosoideae. In: Martius, C. F. P. (ed.). Flora brasiliensis 15(2). Monachii, Regia C. Wolf et Fil., B. Keller. Pp. 458-500.

Burkart, A. 1952. Las leguminosas argentinas. ACME Agency, Buenos Aires, 569p.

1979. Flora Ilustrada CatarinenseLeguminosas, Mimosoideae. 299p.

Carvalho, D. A.; Oliveira-Filho, A. T.; Berg, E.; Fontes, M. A. L.; Vilela, E. A.; Sá, J. J. G. \& Carvalho, W. A. C. 2005. Variações florísticas e estruturais do componente arbóreo de uma floresta ombrófila alto-montana, às margens do rio Grande, Bocaina de Minas, MG, Brasil. Acta Botanica Brasilica 19(1): 91-109.

Custódio Filho, A. \& Mantovani, W. 1986. Flora Fanerogâmica da Reserva do Parque Estadual das Fontes do Ipiranga (São Paulo, Brasil). 81-Leguminosae. Hoehnea 13: 113-140.

Doyle, J. J.; Chappill, J. A.; Bailey, D. C. \& Kajita, T. 2000. Towards a comprehensive phylogeny of legumes: evidence from $r b c \mathrm{~L}$ sequences and non-molecular data. In: Herendeen, P. S. \& Bruneau, A. (eds.). Advances in Legume Systematics. Royal Botanic Gardens, Kew. Pp. 1-20.

Elias, T. S. 1974. The genera of Mimosoideae (Leguminosae) in the southeastern United States. Journal Arnold Arboretum 55(1): 67-118.

Garcia, F. C. P. 1998. Relações sistemáticas e fitogeografia do gênero Inga Miller (Leguminosae, Mimosoideae, Ingeae) nas florestas da costa sul e sudeste do Brasil. Tese de Doutorado. Universidade Estadual Paulista, Rio Claro, 248p.

Gentry, A. H. 1982. Neotropical floristic diversity: phytogeographical connections between Central and South América, pleistocene climatic fluctuations, or an accident of the andean orogeny? Annals Missouri Botanical Gardens 69: 557-593.

Gilhuis, J.P. 1986. Vegetation survey of the Parque Florestal Estadual do Rio Doce, MG, Brasil. Dissertação de Mestrado. Universidade Federal de Viçosa, Viçosa, 112p. 
Giulietti, A. M. \& Forero, E. 1990. "Workshop" diversidade taxonômica e padrões de distribuição das angiospermas brasileiras. Acta Botanica Brasilica 4(1): 3-10.

Herendeen, P. S.; Bruneau, A. \& Lewis, G. P. 2003. Phylogenetic relationships in caesalpinioid legumes: a preliminary analysis based on morphological and molecular data. In: Klitgaard, B. B. \& Bruneau, A. (eds.). Advances in Legume Systematics. Royal Botanic Gardens, Kew. Pp. 37-62.

IEF-MG. 1994. Pesquisas prioritárias para o Parque Estadual do Rio Doce, Brasil. IEFMG, Belo Horizonte, 35p.

Ildis. 2005. International Legumes Database \& Information Service (version 10, november 2005). Disponível http://ildis.org. Acesso em 25 de julho de 2006.

Jesus, R. M \& Garcia, A. 1992. O Herbário da Reserva Florestal de Linhares. In: Anais do $2^{\circ}$ Congresso Nacional sobre Essências Nativas. Instituto Florestal, São Paulo. Pp. 350-362.

Joly, C. A.; Aidar, M. P. M.; Klink, A. A.; Mcgrath, D. G.; Moreira, A. G.; Moutinho, P.; Nepstad, D. C.; Oliveira, A. A.; Pott, A.; Rodal, M. J. N. \& Sampaio, E. V. S. B. 1999. Evolution of the Brazilian phytogeography classification systems: implications for biodiversity conservation. Ciência e Cultura 51 (5/6): 331-48.

Leitão-Filho, H. F. 1982. Aspectos taxonômicos das florestas do estado de São Paulo. Silvicultura em São Paulo 16A(1): 197-206.

Lewis, G. P. 1987. Legumes of Bahia. Royal Botanic Gardens, Kew, 369p.

Lewis, G. P. \& Lima, M. P. 1989. Pseudopiptadenia Rauschert no Brasil (Leguminosae-Mimosoideae). Arquivos do Jardim Botânico do Rio de Janeiro 30: 43-67.

Lewis, G. P. \& Lima, M. P. 1991. Pseudopiptadenia Rauschert no Brasil (Leguminosae). Arquivos do Jardim Botânico do Rio de Janeiro 30: 57.

Lewis, G. P.; Schrire, B.; Mackinder, B. \& Lock, M. 2005. Legumes of the world. Royal Botanic Gardens, Kew, 577p.
Lima, H. C. 2000. Leguminosas arbóreas da Mata Atlântica. Uma análise da riqueza, padrões de distribuição geográfica e similaridades florísticas em remanescentes florestais do estado do Rio de Janeiro. Tese de Doutorado. Universidade Federal do Rio de Janeiro, Rio de Janeiro, 151p.

Lima, M. P. M. \& Lima, H. C. 1984. Parapiptadenia Brenan (Leg-Mim)Estudo taxonômico das espécies brasileiras. Rodriguésia 36(60): 23-30.

Lima, M. P. M.; Guedes-Bruni, R. R.; Sylvestre, L. S. \& Pessoa, S. V. A. 1997. Padrões de distribuição geográfica das espécies vasculares da Reserva Ecológica de Macaé de Cima. In: Lima, H. C. \& Guedes-Bruni, R. R. (eds.). Serra de Macaé de Cima: Diversidade Florística e Conservação em Mata Atlântica. Jardim Botânico do Rio de Janeiro, Rio de Janeiro. Pp. 103-124.

Lombardi, J. A. \& Gonçalves, M. 2000. Composição florística de dois remanescentes de Mata Atlântica do sudeste de Minas Gerais, Brasil. Revista Brasileira de Botânica 23(3): 255-282.

Lopes, W. P.; Silva, A. F.; Souza, A. L. \& Meira-Neto, J. A. A. 2002. Estrutura fitossociológica de um trecho de vegetação arbórea no Parque Estadual do Rio DoceMinas Gerais, Brasil. Acta Botanica Brasilica 16(4): 443-456.

Lorenzi, H. 1992. Árvores brasileiras: manual de identificação e cultivo de plantas arbóreas nativas do Brasil. Vol.1. Plantarum, Nova Odessa, 352p.

Martins, C. S. 2000. Caracterização física e fitogeográfica de Minas Gerais. In: Mendonça, M. P. \& Lins, L. V (eds.). Lista Vermelha das espécies ameaçadas de extinção da flora de Minas Gerais. Belo Horizonte: Fundação Biodiversitas, Zôo-Botânica. Pp. 35-43.

Martins, E. M. O. 1974. Stryphynodendron Mart. (Leguminosae: Mimosoideae) As espécies do nordeste, sudeste e sul do Brasil II. Leandra 3-4(4-5): 53-60. 1981. Stryphynodendron Mart. (Leguminosae: Mimosoideae) com 
especial referência aos taxa amazônicos. Leandra 10-11: 3-100.

Meira-Neto, J. A. A.; Souza, A. L.; Silva, A. F. \& Paula, A. 1997a. Estrutura de uma floresta Estacional Semidecídua Aluvial, em área diretamente afetada pela Usina Hidrelétrica de Pilar, Ponte Nova, Zona da Mata de Minas Gerais. Revista Árvore 21(2): 213-220.

.1997b. Estrutura de uma floresta Estacional Semidecídua Submontana, em área diretamente afetada pela Usina Hidrelétrica de Pilar, Ponte Nova, Zona da Mata de Minas Gerais. Revista Árvore 21(3): 337-344.

.1997c. Estrutura de uma floresta Estacional Semidecídua Insular, em área diretamente afetada pela Usina Hidrelétrica de Pilar, Ponte Nova, Zona da Mata de Minas Gerais. Revista Árvore 21(4): 493-500.

Meira-Neto, J. A. A. \& Martins, F. R. 2002. Composição florística de uma floresta estacional montana no município de ViçosaMG. Revista Árvore 26(4): 437-446.

Mello, C. L. 1997. Sedimentação e tectônica cenozóicas no médio vale do rio Doce (MG, Sudeste do Brasil) e suas implicações na evolução de um sistema de lagos. Tese de Doutorado. Universidade de São Paulo, São Paulo, 275p.

Mendonça Filho, C. V. 1996. Braúna, Angico, Jacarandá e outras leguminosas de Mata Atlântica: Estação Biológica de Caratinga, Minas Gerais. Fundação Botânica Margaret Mee; Fundação Biodiversitas, Belo Horizonte, 100p.

Mendonça, R. C.; Felfili, J. M.; Walter, B. M. T.; Silva Jr., M. C.; Rezende, A. V.; Filgueiras, T. S. \& Nogueira, P. E. 1998. Flora vascular do cerrado. In: Sano, S. M. \& Almeida, S. P. (eds.). Cerrado: ambiente e flora. Embrapa-CPAC, Planaltina. Pp. 289-539.

Mesquita, A. L. 1990. Revisão taxonômica do gênero Enterolobium Mart. (Mimosoideae) para a região neotropical. Dissertação de Mestrado. Universidade Federal Rural de Pernambuco, 222p.
Morim, M. P. 2006. Leguminosae arbustivas e arbóreas da floresta atlântica do Parque Nacional do Itatiaia, Sudeste do Brasil: padrões de distribuição. Rodriguésia 57(1): 27-45.

Nunes, S. R. D. F. S. 2003. As Mimosoideae (Leguminosae) no Parque Estadual do Rio Doce, Minas Gerais, Brasil. Dissertação de Mestrado. Universidade Federal de Viçosa, Viçosa, 106p.

Oliveira-Filho, A. T.; Almeida, R. J.; Melo, J. M \& Gavilanes, M. L. 1994b. Estrutura fitossociológica e variáveis ambientais em um trecho de mata ciliar do córrego dos Vilas Boas, Reserva Biológica do Poço Bonito, Lavras (MG). Revista Brasileira de Botânica 17(1): 67-85.

$\&$ Fontes, M. A. L. 2000. Patterns of floristic differentiation among Atlantic Forests in Southeastern Brazil an the influence of climate. Biotropica 32(4b): 793-810.

\& Machado, J. N. M. 1993. Composição florística de uma floresta semidecídua submontana, na serra de São José, Tiradentes, Minas Gerais. Acta Botanica Brasilica 7(2): 107-118.

\& Ratter, J. A. 1995. A study of the origin of central Brazilian forests by the analysis of plant species distribution patterns. Edinburgh Journal of Botany 32(2): 141-194.

; Scolforo, J. R. S. \& Mello, J. M. 1994c. Composição florística e estrutura comunitária de um remanescente de floresta semidecídua Montana em Lavras, MG. Revista Brasileira de Botânica 17(2): 167-182.

; Vilela, E. A.; Gavilanes, M. L. \& Carvalho, D. A. 1994a. Camparison of the woody flora and soils of six areas of montane semideciduous forest in southern Minas Gerais, Brazil. Edinburgh Journal of Botany 51(3): 335-389.

Peixoto, A. L. \& Gentry, A. 1990. Diversidade e composição florística na mata de tabuleiro na Reserva Florestal de Linhares 
(Espírito Santo, Brasil). Revista Brasileira de Botânica 13: 19-25.

Pennington, T. D. 1997. The genus Inga: Botany. Royal Botanic Gardens, Kew, 844p.

Polhill, R. M. \& Raven, P. H. 1981. Advances in Legume Systematics. Royal Botanic Gardens, Kew, 1049p.

Prado, D. E. \& Gibbs, P. E. 1993. Patterns of species distributions in dry seasonal forests of South America. Annals of Missouri Botanical Garden 80: 902-27.

Rico Arce, M. L. 2001. El género Acacia (Leguminosae, Mimosoideae) en el estado de Oaxaca, México. Anales Jardim Botanico Madrid 58(2): 251-302.

Rocha, Y. T. \& Cavalheiro, F. 2001. The historical aspects of the Botanical Garden of São Paulo. Revista Brasileira de Botânica 24 (4): 577-586.

Secretaria do Estado da Agricultura. 1980. Zoneamento Agroclimático do Estado de Minas Gerais. Belo Horizonte, 114p.

Sevilha, A. C.; Paula A.; Lopes, W. P. \& Silva, A. F. 2001. Fitossociologia do estrato arbóreo de um trecho de floresta estacional no Jardim Botânico da Universidade Federal de Viçosa (face sudoeste), Viçosa, Minas Gerais. Revista Árvore 25(4): 431-443.

SIF/IEF. 1990. Plano Diretor do Parque Florestal Estadual do Rio Doce. Viçosa, 99p.

Silva, A. S. L. 1990. Contribuição ao estudo sistemático das espécies do gênero Acacia Mill. (Leguminosae-Mimosoideae), ocorrentes na Amazônia brasileira. Boletim Museu Paraense Emílio Goeldi Série Botânica 6(2): 159-226.
Silva, A. F. 2000. Floresta Atlântica. In: Mendonça, M. P. \& Lins, L. V. (eds.). Lista vermelha das espécies ameaçadas de extinção da flora de Minas Gerais. Belo Horizonte: Fundação Biodiversitas, ZôoBotânica. Pp. 45-53.

Silva, A. F.; Oliveira, R. V.; Santos, N. R. L. \& Paula, A. 2003. Composição florística e grupos ecológicos das espécies de um trecho de floresta semidecídua submontana da Fazenda São Geraldo, Viçosa, MG. Revista Árvore 27(3): 311-319.

Sneath, P. H. A \& Sokal, R. R. 1973. Numerical Taxonomy. San Francisco: W.H. Freeman Co. 345p.

Veloso, H. P.; Rangel Filho, A. L. R. \& Lima, J. C. A. 1991.Classificação da vegetação brasileira, adaptada a um sistema universal. Instituto Brasileiro de Geografia e Estatística, Rio de Janeiro, 116p.

Wojciechowski, M. F. 2003. Reconstructing the phylogeny of legumes (Leguminosae): an early $21^{\text {st }}$ century perspective. In: Klitgaard, B. B. \& Bruneau, A. (eds.). Advances in Legume Systematics. Part 10. Royal Botanic Gardens, Kew. Pp. 5-35.

Wojciechowski, M. F.; Lavin, M. \& Sanderson, M. J. 2004. A phylogeny of Legumes (Leguminosae) basead on analysis of the plastid mat- $K$ gene resolves many well-supported subclades within the family. American Journal of Botany 91(11): 1846-1862.

Zarucchi, J. L. 1993. Monography in Systematic Botany. Missouri Botanical Garden 45: 44-527. 